\title{
COMUNICAÇÃO, MÍDIA E CIDADANIA NA PRÁTICA PEDAGÓGICA
}

\author{
Divino Alves Bueno \\ Secretaria de Estado da Educação de Goiás (SEDUC), Goiânia, \\ Goiás, Brasil
}

\begin{abstract}
Resumo: A contemporaneidade, cada vez mais midiática, tem colocado grandes desafios para a educação e comunicação. Um deles é o de compreender as mediações comunicacionais constitutivas dos processos educacionais. Atualmente, torna-se imprescindível para os educadores, mais do que compreender, apropriar-se das novas e dinâmicas linguagens que circulam de modo cada vez mais frequente, no contexto da sala de aula e para além dela. Nesse contexto marcado pela cultura digital, refletir, estudar e compreender as interfaces entre educação e comunicação parece um desafio urgente e fundamental para os educadores. Este artigo tem por finalidade empreender um esforço no sentido de explicitar a relação intrínseca existente entre educação, mídia e cidadania no processo educativo.
\end{abstract}

Palavras-Chave: Educação. Comunicação. Mídia. Cidadania.

Entende-se que a evolução da tecnologia midiática ampliou as formas e as possibilidades de comunicação e de aprendizagem entre as pessoas, propiciando formas para que a aprendizagem aconteça em diferentes espaços, seja nos limites físicos da sala de aula, seja, também, em ambientes virtuais, apoiados, principalmente pela internet. Esse novo ecossistema educativo comunicacional, que se forma a partir das interfaces comunicação e educação, possibilita maior aproximação da sala de aula com a realidade vivida 
pelos nossos alunos, mas este é um dos maiores desafios enfrentados pela maioria dos professores.

Para Soares (1999), essas mudanças demandaram o surgimento na educação de um novo campo de atuação, no qual a escola deixa de se limitar a quatro paredes, o local exclusivo da transmissão de saberes, para se transformar em um espaço de mediação, integrando as tecnologias de comunicação em seu processo formativo, resultando, assim, em um

novo espaço de intervenção social, associando a Comunicação e a Educação num campo interdiscursivo e interdisciplinar não respeitando, na verdade, as fronteiras da formalidade das situações e dos projetos educativos, na perspectiva de toda relação comunicativa pode transformar-se numa relação educativa e toda ação educativa deveria transformar-se em ação comunicativa (SOARES, 1999, p. 3, grifo nosso).

Esta relação educativa pressupõe o diálogo, mas é fundamental lembrarmos que um diálogo acontece entre sujeitos situados historicamente, entre quem se interessa pelo que o "outro" tem a dizer sobre si e sobre o mundo em que está inserido. Para Linhares (2007), a relação entre comunicação e educação revela-se como um novo momento, que propõe um processo de apropriação de códigos comunicacionais, dotado de uma visão crítica que contribua para a compreensão da sociedade em que vivemos. Assim, o desafio é conhecer as novas tecnologias e suas linguagens comunicacionais, os novos aparatos tecnológicos, que ampliam as possibilidades de comunicação do homem, modificando a produção e o consumo de produtos simbólicos. Segundo o autor, estamos em um mundo em que os meios de comunicação, que utilizam imagens, som e informações, estão cada vez mais presentes em nosso cotidiano.

MíDIA E CIDADANIA: UMA MATRIZ DE CULTURA

O século XXI inicia-se com grandes desafios para os campos da educação e da comunicação e nos provoca no sentido de refletirmos acerca do que o homem faz com os meios de comunicação e suas mensagens. Questões dessa natureza têm sido amplamente discutidas e investigadas por autores como Martin-Barbero (2009), Orozco (2005), Penteado (2001), 
Setton (2010), Orofino (2005), Citelli (2010), Baccega (2009), Toschi (2009), dentre outros.

Pensar em cidadania nos remete às mudanças sociais ocorridas nas três últimas décadas, dentre elas a "revolução tecnológica" e seus desdobramentos nos campos da comunicação e da educação. Levy (2003) alerta para a discussão a respeito da característica de uma sociedade civil planetária, na qual o ciberespaço aparece "muito mais inclusivo do que os outros meios de comunicação anteriores. Ele permite a expressão pública a todos os indivíduos, grupos, instituições e comunidades" (LEVY, 2003, p. 375). O autor afirma, ainda, que "estas ágoras virtuais contribuem para desenvolver uma cultura de diálogo, pois reúnem os internautas por temas de debate, habituando-os a trocar ideias com cidadãos que não partilham suas ideias" (LEVY, 2003, p. 381). Se os atuais meios de comunicação tendem a ser mais inclusivos, conforme afirma Levy, isso significa que o desafio do professor, de certo modo, já está delineado, ou seja, não é uma questão de acesso, mas, sim, de uso dos meios como mais uma das possibilidades de construção de conhecimento e de realização da cidadania e da emancipação do homem.

De acordo com Morigi e Rosa (2004, p. 82),

a mídia, entendida como um espaço discursivo representa talvez a principal esfera de produção de sentidos a partir da qual também se pode construir a cidadania. Exerce assim uma função social, podendo remodelar os processos sociais e as práticas culturais, potencializando informações vinculadas à educação e voltadas para a formação da cidadania

Nessa perspectiva, a comunicação midiática possibilita a elaboração de muitos dos discursos tidos como legítimos na atualidade. Segundo Morigi e Rosa (2004, p. 84)"no espaço público midiatizado, os campos e atores sociais confrontam-se com uma difícil e simultânea convivência entre inclusão e exclusão, liberdade e coação, autonomia e dependência". Esse campo, embora complexo e nebuloso, no nosso entendimento é um campo que nos desafia a buscar o aprofundamento e a ampliação da compreensão acerca da natureza dos meios, de seus conteúdos e impactos na formação das pessoas.

Para Setton (2010), as grandes transformações ocorridas nos dois últimos séculos têm como consequência principal o fenômeno midiático, 
colocando as mídias em destaque, não só pela imponente presença em nosso cotidiano, mas pelas mudanças culturais e seu impacto nas questões educacionais.

Thompson (1998) traça o perfil das transformações que ele chama de organização social e poder simbólico. Procura mostrar que o desenvolvimento dos meios de comunicação, desde a mais remota forma de impressão até as recentes comunicações eletrônicas, surge como parte integral da sociedade moderna. Para o autor, o desenvolvimento dos meios de comunicação se entrelaça, de maneira complexa, com outros processos, de tal forma que, considerado em sua totalidade, constitui o que se chama "modernidade". Processo que leva o autor a definir a mídia como fundamentalmente "cultural", pois se ocupa, ao mesmo tempo, com aspectos significativos das formas simbólicas e com a contextualização social.

Para Setton (2010, p. 13), entender as mídias como uma nova matriz de cultura é

considerá-las um sistema de símbolos com linguagem própria distinta das demais matrizes de cultura (imagem, som, texto e a mistura de todas eles) que compõem o universo socializador do indivíduo contemporâneo. [...] Além disso, engloba as mercadorias culturais com a divulgação de produtos e imagens e os meios eletrônicos de comunicação, ou seja, jogos eletrônicos, celulares, DVDs, CDs, TV a cabo ou via satélite e, por último, os sistemas que agrupam a informática, a TV e as telecomunicações - computadores e redes de comunicação.

A autora, ao tratar da relação das mídias com a educação, ressalta a importância de analisar a cultura das mídias como um estudo integrado das formas simbólicas, originárias de um processo historicamente específico, que se constitui de formas simbólicas produzidas, difundidas e consumidas pela sociedade. A autora afirma que compreender a cultura midiática pode ser um caminho para entender a sociedade em que vivemos. Se a compreensão da cultura midiática nos auxilia na compreensão da sociedade em que vivemos, então, pode-se inferir que, nos auxilia, também, a entender seu papel nos processos de ensino e de aprendizagem.

Para Guareschi (2006), a mídia é um fenômeno abrangente e penetrante, e nada escapa dela, pois tem sempre algo a dizer a qualquer instância 
da sociedade moderna, perpassando situações individuais e sociais, possuindo um papel fundamental e sempre crescente por suas formas simbólicas. Segundo o autor, a comunicação é o instrumento e a relação fundamental para concretização dessas trocas simbólicas.

Guareschi (2006) afirma, ainda, que a informação e a comunicação foram os grandes responsáveis pela geração das novas tecnologias, e é a informação o novo propulsor do desenvolvimento da produtividade do sistema capitalista de hoje. Segundo o autor, houve um tempo em que a terra era a fonte da produtividade; depois foi a vez da indústria se responsabilizar pelo desenvolvimento. Hoje,

o modo de desenvolvimento fundamental, isto é, o fator de produtividade primordial, éa informação. Quem detém a informação, detém o fator central de desenvolvimento. A internet, por exemplo, está modificando a forma como as pessoas se relacionam, como aprendem, como compram, como consultam médico e até mesmo como as pessoas fazem sexo (GUARESCHI, 2006, p. 29).

Diante desta abrangência midiática, Setton (2010) formula as seguintes questões: estaríamos vivendo em um mundo em que a difusão e a rapidez da informação, em termos globais, levariam toda a sociedade a se tornar homogênea, ou seja, uma sociedade em que todos pensariam igualmente? Estaríamos vivendo sob o domínio e o interesse de uma grande máquina de sentidos, que seriam as mídias? Ou diferenças locais, sociais, éticas etc. seriam os filtros de formas diferenciadas de recepção, apropriação e compreensão dos sentidos e valores propostos?

A autora afirma não acreditar em uma leitura apocalíptica sobre nossos destinos. Acredita nos processos de reapropriação e ressignificação dos sentidos e conteúdos da cultura das mídias. O que nos leva a concluir que os consumidores dos produtos midiáticos não são passivos. Ou seja, os conteúdos das mensagens são interpretados pelos sujeitos a partir do referencial cultural e dos valores adquiridos em outras instâncias socializadoras.

Setton (2010) entende a mídia como aparato simbólico e material de caráter cultural, com uma produção de cultura que, veiculada pelos diversos 
meios, possibilita a disseminação de modelos de estilos de vida, ideias e referências de padrões de comportamento. Neste sentido, a autora relaciona as mídias com a educação, por considerá-las agentes sociais da educação, e desenvolverem no mundo contemporâneo funções educativas e de socialização. Trata-se de um tema interdisciplinar, complexo e controverso.

Segundo a autora, as mídias

junto com a família, a religião e a escola, funcionam como instâncias transmissoras de valores, padrões e normas de comportamentos e também servem como referências identitárias. [...] As mídias, então, são tão poderosas quanto seus companheiros de prática pedagógica, como a família e a escola, por exemplo. A particularidade do mundo contemporâneo é que essas instâncias vivem hoje em uma tensa e intensa rede de interdependência com as outras agências socializadoras, agindo simultaneamente na formação moral e cognitiva do indivíduo na atualidade (SETTON, 2010, p. 8).

É importante que os professores e os comunicólogos compreendam a importância da mídia na formação cultural das crianças, jovens e adultos, pois cada vez mais, ela tem transmitido saberes, novos padrões de comportamento e produzido sentidos.

Para Martin-Barbero, no campo da cultura, o erudito, o massivo e o popular não podem mais ser compreendidos separadamente, visto que nas sociedades contemporâneas a mídia, ela própria, se constitui em um elemento de cultura que, ao transformar os modos anteriores, se constitui ela própria em uma nova forma cultural. O que é importante para nós educadores é compreender como estas novas formas culturais sustentam velhos conteúdos e os preconceitos de classe, gênero, orientação sexual, étnicos, geracionais, entre outros (OROFINO, 2005, p. 59).

Para Orofino (2005), a relação entre mídia e educação pode acontecer de várias formas, sendo de complementaridade ou de ruptura. Como instâncias educativas, mídias e educação podem ser aliadas ou viver em constante conflito, mas, podem conviver e coexistir desenvolvendo práticas comuns ou discordantes. Diante dessa perspectiva, a autora afirma que não se pode mais conviver com discussões simplistas que atribuem uma importância irreal às mídias sem a devida compreensão da complexidade das relações que elas mantêm com outras instâncias e situações da vida dos sujeitos. 
Na perspectiva de utilização de recursos midiáticos nos processos educativos, surge um novo campo de diálogo, de crítica, de pesquisas e estudos: um novo campo de interface de abrangência entre comunicação e educação. Esse ângulo comunicacional educativo possibilita uma formação crítica frente às mídias, em uma perspectiva de construção e afirmação da cidadania, e de valorização da cultura.

Neste sentido, a escola não pode se isentar da responsabilidade social. Como agente de socialização que é, deve discutir, orientar e mediar as trocas de saberes presentes nas múltiplas linguagens midiáticas.

A educação, hoje, deverá atender às exigências sociais do mundo globalizado, oferecendo uma formação para e pela cidadania e a dignidade humana. Para isso, a educação não pode ficar às margens do desenvolvimento dos meios de comunicação. Pelo contrário, deve-se apegar a essa mola propulsora da evolução tecnológica para tornar-se um espaço de apropriação dos saberes que levam à formação da ética e da cidadania, que transcendem o individualismo e o egoísmo, o espaço e o tempo, que atendem às demandas de "toda sociedade e em toda cultura, sem exclusividade nem rejeição, segundo modelos e regras próprias a cada sociedade e a cada cultura" (MORIN, 2000, p. 13).

Estas reflexões são importantes e contribuem para entender a sociedade e os processos de comunicação e de educação, principalmente, quando atribuem a construção e reprodução da vida social à interação dos processos de comunicação e aprendizagem, legitimando as práticas cotidianas que constituem a cultura. Os processos de aprendizagem e de apropriação do conhecimento passam a ser repensados e entendidos, também, como processos de comunicação.

Por isso, a questão não é mais discutir a inserção ou não das TICs na educação, mas sua apropriação, pelos sujeitos pedagógicos (alunos e professores), no sentido de promover melhoria na qualidade dos processos educativos e, consequentemente, da aprendizagem. Para tanto, é necessário discutir, compreender e avaliar a importância da comunicação nos processos educacionais.

Os processos midiáticos são atos de troca que exigem negociação de informações. As mídias são consideradas como agente do diálogo e da 
mediação com seus consumidores e tem como característica os atos da reciprocidade e da troca de mensagens, códigos e saberes. Assim como a prática pedagógica docente, as mídias exprimem uma ideia, um conteúdo, e possuem a intenção de transmitir, divulgar conhecimentos, habilidades e competências (SETTON, 2010).

Percebe-se, em nossa prática pedagógica, que as crianças e adolescentes, mesmo estando na condição de "nativos digitais"1 , com facilidades de lidar com as mais complexas tecnologias, necessitam passar por um processo de letramento digital. São consumidores compulsivos de inúmeras tecnologias e mídias, muitas vezes sem compreender que são recursos, ferramentas ou interfases para a aprendizagem. Para eles, é comunicação e entretenimento. Da mesma forma, os professores, também, consomem essas mesmas mídias e tecnologias, porém, não as reconhecem e, às vezes, as rejeitam como recurso didático capaz de dinamizar o cotidiano da sala de aula, como instrumentos de mediação dos processos de ensino-aprendizagem, o que aproximaria sua prática da realidade de seus alunos.

Segundo Citelli (2010), as influências exercidas pelas mídias devem ser olhadas em contextos culturais mais amplos e vistas como a singularidade técnica e tecnológica que marca a contemporaneidade. Para o autor, devemos fugir das visões moralizantes e do encantamento acrítico que atribui à tecnologia certo messianismo, como se ela, por si só, resolvesse os problemas pedagógicos da educação.

As transformações têm ocorrido de maneira contínua e com tal rapidez que dificulta não só nossa compreensão desse fenômeno, mas, também, o enfrentamento de velhos paradigmas, pois se mudam as formas de interação e de adaptação ao mundo.

Na análise de Baccega (2009), nos últimos tempos tem se observado um confronto entre as tradicionais agências de socialização - escola e família e os meios de comunicação, hoje consolidados, também, como outra agência de socialização. Uma disputa pela hegemonia na formação dos valores dos sujeitos quer destacar-se na sociedade. Essa situação parece amenizar-se no campo da comunicação e educação, que "justifica e procura pistas para 
o diálogo entre as agências, para um intercâmbio entre elas, de modo a beneficiar a formação dos sujeitos sociais mais críticos" (BACCEGA, 2010, p. 53).

É preciso compreender que os meios de comunicação têm realizado um tipo de educação desvinculada dos sistemas oficiais de ensino. Ignorados tanto pela escola quanto pela família, estes meios tornaram-se uma nova agência de socialização e educação.

A escola, entretanto, em grande parte, continua fundamentada na perspectiva tradicional de ensino em que a tecnologia é vista como um fim em si mesmo e não como meio e isso dificulta a realização de uma educação pautada na perspectiva de formação crítica, uma educação que instrumentalize os alunos para que construam sua autonomia e emancipação na sociedade contemporânea e mediatizada. Uma formação capaz de proporcionar ao educando habilidade e competência para realizar uma releitura crítica dos meios de comunicação, percebendo a realidade construída por meios de filtro e "editada" por superestruturas, como afirma Guareschi e Biz (2005) e Bacegga (1994).

Para Baccega (2009), a forte presença dos meios de comunicação na cultura contemporânea, além de colocá-los na posição de agência de socialização, torna-os, também, educadores, participando assim da construção da cidadania. Ainda nessa perspectiva, Martin-Barbero (2006), afirma que a comunicação tem se apresentado como um novo espaço de cidadania. Logo, surge a necessidade de se colocar em sintonia mídia e escola, agora mais do que nunca, por reconhecer que a escola não é mais o único lugar do saber, e que a utilização dos meios de modo propositivo pode significar novas possibilidades de construção do conhecimento, de exercício da autonomia e da cidadania.

É inegável que as mídias realizam um tipo de educação diferente do sistematizado pelos sistemas educacionais, entretanto, Guareschi e Biz (2005) mostram que a função da mídia é distinta da educação, não sendo possível exigir as mesmas responsabilidades. A instituição escolar deve abrir-se para a multiplicidade da realidade, interagindo com outras instituições sociais para se tornar mais interessante para os alunos. Para isso, a escola deve mo- 
dificar a filosofia e a metodologia educativa, aproveitando, assim, as novas tecnologias (Orozco 2005).

É preciso reconhecer que, apesar de não ter a mesma função que a escola, as mídias apresentam um potencial educativo, à medida que empresta aos projetos pedagógicos suas múltiplas linguagens. É fundamental, entretanto, avançarmos na compreensão de que as mudanças devem ultrapassar os aspectos técnicos do uso, ou seja, devem extrapolar o uso instrumental, de forma a possibilitar a descoberta de um novo sensorium, um espaço de emancipação, apropriação e de construção do conhecimento, em que os sujeitos pedagógicos (professor e aluno) participam ativamente.

Apropriar-se dessa compreensão - de que as mídias podem contribuir para a cidadania - é a essência da inserção das mídias na educação, pelo menos, em dois aspectos: o acesso e a democratização consciente da comunicação e informação; e a mediação do imaginário e do real, e do ético e do estético (BELLONI, 2009).

Segundo Martin-Barbero (2006), na sociedade contemporânea, as mídias configuram-se como um novo espaço público e de cidadania. Trata-se de uma nova cidadania e de um novo espaço público, recheado de uma pluralidade de atores e de leituras críticas que convergem para um compromisso emancipador. Impulsionada pelas tensões provocadas pelas mutações tecnológicas, a comunicação começou a ocupar um lugar estratégico nos novos modelos de sociedade. Trata-se de um direito de todos, "oxigênio democrático", mesmo estando sob gestão da esfera privada (MELO; TOSTA, 2008).

Morigi e Rosa (2004) afirmam que a relação entre informação e cidadania não acontece somente a partir do acesso e da utilização de informações. Segundo as autoras, para que a informação seja capaz de contribuir na construção de espaços sociais de cidadania, dois movimentos básicos são necessários. O primeiro está relacionado com o polo de produção da informação, que dever ser produzida para a ação política. $O$ segundo, diz respeito ao polo da recepção, exigindo do cidadão uma postura ativa, no sentido de não apenas receber, mas de analisar criticamente as informações.

Segundo os autores, a relação entre cidadania e informação depende da capacidade do receptor utilizar suas representações simbólicas de expe- 
riências vividas e de informações recebidas, que serão transformadas em discursos de sua realidade. Assim, "na relação entre informação e a cultura, as experiências da vida cotidiana se estreitam através da comunicação" (MORIGl; ROSA, 2004, p. 87).

Nesta perspectiva, observa-se que entre os meios de comunicação, o rádio apresenta características que favorecem a questão da cidadania. Em relação à participação, Bertolt Brecht (2005) já vislumbrava a ideia de uma comunicação voltada para o coletivo, que atendesse às necessidades da sociedade. Para o autor, o rádio deveria funcionar em dupla direção, ou seja, um canal de emissão e transmissão de informações, mas que, também, permitisse a participação do ouvinte na programação.

A abrangência e o potencial de produção e circulação de informações colocam as mídias, na opinião de muitos, como um quarto poder, por meio do qual o cidadão busca as soluções para problemas não resolvidos pelo Estado. Para Melo e Tosta (2008), entretanto, a mídia não é bem um quarto poder, pois, para isso, ela deveria se sobrepor aos outros poderes constituídos (Legislativo, Executivo e Judiciário), que a monitoram, na tentativa de evitar que se torne um poder paralelo.

Segundo Melo e Tosta (2008, p. 38), é crescente o movimento chamado "vigilância cidadã". Trata-se da vigilância midiática exercida pela cidadania, em que o cidadão sabe do poder que tem, podendo em "certas circunstâncias, calar a boca da mídia". Significa que o cidadão se manifesta contra ou a favor de uma causa disseminada pela mídia. Segundo os autores, mesmo não conseguindo despertar o interesse, ou obter sucesso, os cidadãos podem levantar o problema.

Para Orofino (2005), a escola precisa de uma pedagogia que responda às expectativas do tempo histórico no qual está inserida. Segundo Paul Willis (1990), citado por Orofino,

as mídias culturais onipresentes da era eletrônica fornecem um vasto leque de recursos simbólicos e são um poderoso estimulante para o trabalho simbólico e criativo dos jovens. As mídias ajudam a mediar as novas possibilidades de uma cultura comum. [...] As mídias penetram virtualmente quase todas as suas atividades mais criativas. Mas na mesma medida em que as mídias convidam a certas interpretações, os jovens não apenas aprenderam seus 
códigos mas aprenderam a brincar com a interpretação desses códigos, a recriar formas, a inter-relacionar a mídia com sua própria estética de base. Eles acrescentam e desenvolvem novos significados àqueles que lhes são dados (WILLIS, 1990, apud, OROFINO, 2005, p. 132).

A mídia ocupa um lugar cada vez mais significativo na formação cultural das crianças e jovens. Nesse sentido, a escola deve e tem possibilidade de ampliar e intensificar o diálogo entre a cultura escolar e a cultura midiática ao possibilitar oportunidades de construção de narrativas de autoria dos estudantes com uso de novas linguagens e tecnologias (OROFINO, 2005).

Segundo Orofino (2005), a escola é o espaço de encontro de muitos sistemas simbólicos, ou seja, muitas culturas, representadas pela identidade dos diferentes alunos e professores, pela cultura erudita ali ensinada, a cultura popular da comunidade onde a escola está inserida. Para a autora, esse sistema torna-se ainda mais complexo quando considerada a dimensão da cultura midiática presente em nossos dias, visto que $98 \%$ do território brasileiro são cobertos pelas transmissões da TV e do rádio, que levam diariamente, informações, entretenimento, valores éticos e políticos aos mais distantes lugares do país. Logo, não há escola que não receba as influências da cultura das mídias, afirma a autora.

Para essa autora, a escola como local de encontro de "muitas culturas", é, também, o espaço das mediações, que se dão por meio das trocas de saberes entre os pares, nos pátios, em jogos e brincadeiras, nas conversas informais. Entretanto,

a escola subestima esta condição e deixa este papel social relegado ao espontaneísmo do dia a dia, sem potencializar sua condição mediadora e sem assumir a responsabilidade sobre isto. Desta forma a escola torna-se muito mais um espaço de mediação situacional do que institucional. Uma vez que as mediações ocorrem muito mais no pátio da escola do que na sala de aula (OROFINO, 2005, p. 65, grifo do autor).

A autora alerta, contudo, que, ao concordarmos com esta condição, corremos o risco de nos aproveitarmos de uma situação mais cômoda, porém, de forma menos responsável. Para ela, na condição de educadores críticos, devemos assumir a responsabilidade institucional da escola nestas mediações, 
ampliando as possibilidades de ressemantização, diálogo, debate e resposta sobre o que os alunos recebem, diariamente, da mídia.

Martin-Barbero (2006) discorre sobre um ambiente de informação que recebe e mistura vários saberes e diversas formas de aprender. Um saber disperso e fragmentado que circula fora dos lugares sagrados que antes o detinha.

A escola está deixando de ser o único lugar de legitimação do saber, já que há uma variedade de saberes que circulam por outros canais, difusos e descentralizados. A diversificação e a difusão do saber, fora da escola, são dois dos desafios mais fortes que o mundo da comunicação propõe ao sistema educativo. Saberes-mosaico, [...] que está acarretando na escola, não uma abertura a esses novos saberes, mas, sim, uma posição defensiva, e a construção de uma ideia negativa e moralista de tudo que a questiona em profundidade, desde o ecossistema comunicativo das mídias e das tecnologias de comunicação e informação (MARTIN-BARBERO, 2006, p. 56).

A afirmação de Martin-Barbeiro intensificou-se nas duas últimas décadas do século XX, com a evolução dos meios de comunicação. Estas mudanças abalam as estruturas fechadas que constituem nosso sistema educacional. Segundo Valente (1999), a educação sofre e se adéqua às concepções paradigmáticas segundo as quais vive a sociedade. Assim, ela passa pelas mesmas transformações que outros segmentos da sociedade civil.

Na educação escolar, o desafio é consolidar a escola como um espaço de compreensão e apropriação das multifacetadas linguagens provenientes das mutações tecnológicas que caracterizam a contemporaneidade.

Diante das questões expostas, considera-se cada vez mais necessário ampliar as discussões em torno da relação entre mídia e educação, um desafio - para os sistemas de ensino, a escola e o professor - que consiste em compreender que o tempo dedicado pelo aluno no consumo da mídia supera o preenchido pela escola. Logo, é importante "vale a pena refletir sobre a natureza da educação coletiva implícita nesse espaço que McLuhan chamou apropriadamente de aula sem paredes" (MELO; TOSTA, 2008, p. 79).

As afirmações de Melo e Tosta (2008) reforçam a necessidade de refletirmos sobre as interfaces da Educação e Comunicação, como um campo de possibilidades, no qual alunos têm a oportunidade de compreender a 
dinâmica da produção midiática, ampliando sua consciência crítica em relação às mensagens que circulam nas mídias.

Considerando que a mídia constitui-se em um novo espaço público e de cidadania, principalmente com o crescimento dos sites de redes sociais, entendemos que a consolidação deste novo sensorium passa necessariamente pela conscientização crítica e criativa dos usuários (receptores), e que o caminho mais propício para se alcançar esta consciência seja a escola. Mas, para isso, é necessária a formação continuada de professores, valorizando a reflexão sobre a ação pedagógica, de modo que as habilidades operacionais não sejam tomadas como a centralidade do processo educativo das mídias em sala de aula.

\section{COMUNICATION, MEDIA AND CITIZENSHIP IN PEDAGOGICAL PRACTICE}

ABSTRACT:The contemporary world, increasingly mediatic, has placed great challenges for communication, education and citizenship. One is to understand the communicational mediation constitutive of educational processes. At present, it is essential for educators, more than to understand, to appropriate the new dynamic languages that circulate so increasingly frequent in the context of the classroom and beyond. In this context, marked by digital culture, reflecting, studying and understanding the interfaces among communication, education and citizenship seem a fundamental and urgent challenge for educators. This research aims to undertake an effort to explain the intrinsic relationship between education, media and citizenship in the educational process.

KeYwords: Education. Communication. Media. Citizenship.

\section{COMUNICACIÓN, MEDIOS DE COMUNICACIÓN Y LA CIUDADANÍA EN LA PRÁCTICA EDUCATIVA}

RESUMEN: La contemporaneidad, cada vez más mediática, ha colocado grandes desafíos para la educación y comunicación. Uno de ellos es lo de comprender las mediaciones comunicacionales constitutivas de los procesos educacionales. Actualmente, se hace imprescindible para los educadores, más que comprender, apropiarse de los nuevos y dinámicos lenguajes que circulan de modo cada vez más frecuente, en el contexto de la sala de clase y más allá de ella. En este contexto marcado por la cultura digital, reflejar, estudiar y comprender las interfaces entre educación y comunicación parece un desafío urgente y fundamental para los educadores. Este artículo tiene por finalidad 
emprender un esfuerzo en el sentido de explicitar la relación intrínseca existente entre educación, medios de comunicación y ciudadanía en el proceso educativo.

Palabras Clave: Educación. Comunicación. Medios de Comunicación. Ciudadanía.

\section{NOTAS}

1) Gerações que cresceram com as novas tecnologias. Eles passam a vida inteira cercados e usando computadores, vídeo games, tocadores de música digitais, câmeras de vídeo, telefones celulares, e todos os outros brinquedos e ferramentas da era digital (PRENSKY, 2001).

\section{REFERÊNCIAS}

BACCEGA, M. A. Do mundo editado à construção do mundo. Comunicação \& Educacão, São Paulo, v. 1, n. 1, p. 7-14, set./dez. 1994.

Comunicação/educação e a construção de nova variável histórica. Comunicação \& Educação, São Paulo, v. 14, n. 3, p. 19-28, set./dez. 2009.

Comunicação/educação: relações com o consumo: importância para a constituição da cidadania. Comunicação, mídia e consumo, São Paulo, v. 7, n. 19, p. 49-65, jul. 2010.

BELLONI, M. L. O que é mídia-educação. 3. ed. Campinas, SP: Associados, 2009.

CITELLI, A. Comunicação e educação: convergências educomunicativas. Comunicação, Mídia e Consumo, São Paulo, v. 7, n. 19, p. 67-85, jul. 2010.

GUARESCHI, P. A. Mídia e cidadania. Conexão - Comunicação e Cultura, Caxias do Sul, v. 5, n. 9, p. 27-40, jan./jun. 2006.

; BIZ, O. Mídia, educação e cidadania: tudo o que você deve saber sobre mídia. Petrópolis: Vozes, 2005.

LÉVY, P. Pela Ciberdemocracia. In: MORAES, D. (Org.). Por uma outra comunicação: mídia, mundialização, cultura e poder. Rio de Janeiro: Record, 2003. p. 367-384.

LINHARES, R. N. Gestão em comunicação e educação: o audiovisual no espaço escolar. Maceió: EDUFAL, 2007.

MARTIN-BARBERO, J. Tecnicidades, identidades, alteridades: mudanças e opacidades da comunicação no novo século. In: MORAES, D. (Org.). Sociedade midiatizada. Rio de Janeiro: Mauad, 2006, p. 51-79.

Dos meios às mediações: comunicação, cultura e hegemonia. Rio de Janeiro: Editora UFRJ, 2009. 
MELO, J. M.; TOSTA, S. P. Mídia \& Educação. Belo Horizonte: Autêntica, 2008.

MORIGI, V.; ROSA, R. Cidadania midiatizada, cidadão planetário. Revista Comunicação e Espaço Público, Ano VII, n. 1/2, 2004.

MORIN. E. Os sete saberes necessários à educação do futuro. São Paulo: Cortez, 2000.

OROFINO, M. I. Mídias e mediações escolar: pedagogia dos meios, participação e visibilidade. São Paulo: Cortez, 2005.

OROZCO, G. G. Mídia, percepção e educação. Revista FAMECOS, Porto Alegre, n. 26, p. 16-23, abr. 2005.

PENTEADO, H. D. (Org.). Pedagogia da comunicação: teorias e práticas. 2. ed. São Paulo: Cortez, 2001.

PORTO, T. M. E. Saberes e linguagens de educação e comunicação. Pelotas: UFPel, 2001.

PRESNKY, Marc. Nativos digitais imigrantes digitais. On the Horizon, NCB University Press, v. 9, n. 5, out. 2001.

SETTON, M. das G. Mídia e educação. São Paulo: Contexto, 2010.

SOARES, Ismar de Oliveira. Uma educomunicação para a Cidadania. São Paulo: Núcleo de Comunicação e Educação da Universidade de São Paulo (NCE/USP), 1999.

THOMPSON, J. B. A mídia e a modernidade: uma teoria social da mídia. Rio de Janeiro-Petrópolis: Vozes, 1998.

TOSCHI, M. S. Leitura na tela dos computadores. In: XVIII Simpósio de Estudos e Pesquisas da Faculdade de Educação. Comunicação apresentada na mesa Formação e Profissionalização Docente. Goiânia: UFG, 2009.

VALENTE, J. A. O computador na sociedade do conhecimento. Campinas, SP: Unicamp/ NIED, 1999.

DIVINO ALVES BUENO: Mestre em Comunicação pela Universidade Federal de Goiás. Atualmente é estatutário nas Secretaria Municipal de Educação e Secretaria de Estado da Educação, atuando principalmente nos seguintes temas: formação de professores, educação a distância, educação básica e tecnologia educacional.

E-mail: divino.bueno@hotmail.com 